\title{
Enhancing the safety, quality and productivity of peri-operative care: a nationally funded research programme of systematic reviews based in University Hospitals of Morecambe Bay
}

\author{
Andrew Smith, FRCA
}

Professor Andy Smith is leading a team of researchers based at the Lancaster Patient Safety Research Unit, undertaking a programme of systematic reviews of peri-operative care. They are working with the Cochrane Collaboration and hope to involve the local NHS community both in preparing the reviews and making use of the findings.

\section{RATIONALE}

Anaesthesia is the largest hospital specialty. It has been estimated that two thirds of all hospital inpatients receive care from anaesthetists during their stay. A recent estimate suggested that 2.9 million patients in the UK receive a general anaesthetic each year. (1) Other work indicated that 234 million surgical operations take place each year globally, including 8.1 million in the UK, 8.3 million in France, and 7.7 million in Germany. ${ }^{(2)}$

Patient safety is paramount within anaesthesia and perioperative care. Practitioners from a variety of other disciplines and specialties work with anaesthetists to deliver patient care, so research findings and their implementation in practice within this specialty will, therefore, have a widespread influence on practice across different specialties.

\section{CHOOSING TOPICS FOR REVIEW}

We have established local and national links to aid the selection of systematic review topics. Several topics have already been contributed by local clinicians and trainees across the UK through the Health Services Research Unit of the Royal College of Anaesthetists. Three anaesthetic trainees are now involved in planning and carrying out their suggested reviews.

We also use research findings from the Lancaster Patient Safety Research Unit and national data on errors to inform our choice of new review questions. We are working with the National Institute for Health and Clinical Excellence (NICE) to carry out reviews that are needed for guidelines in development.

We are developing a patient forum within the local area to suggest topics relevant to patients, comment on results, assist with reviews and help with dissemination.

\section{DISSEMINATION OF RESULTS}

Many of our reviews will be published in the Cochrane Library. We will also publish reviews in relevant scientific journals and conferences. Our results, particularly when we highlight an inadequate evidence base, may help prioritise the research agenda both locally and for national funders.

\section{GOALS OF PROGRAMME}

We are working on a series of systematic reviews investigating perioperative care and aim to:

- identify clinical questions in perioperative care where there is uncertainty about best practice

- summarise the available evidence mainly from randomised controlled trials

- disseminate results to clinicians and health policymakers

- highlight topics where further research is needed

- build research capacity in the health service

\section{Inputs \& dissemination}

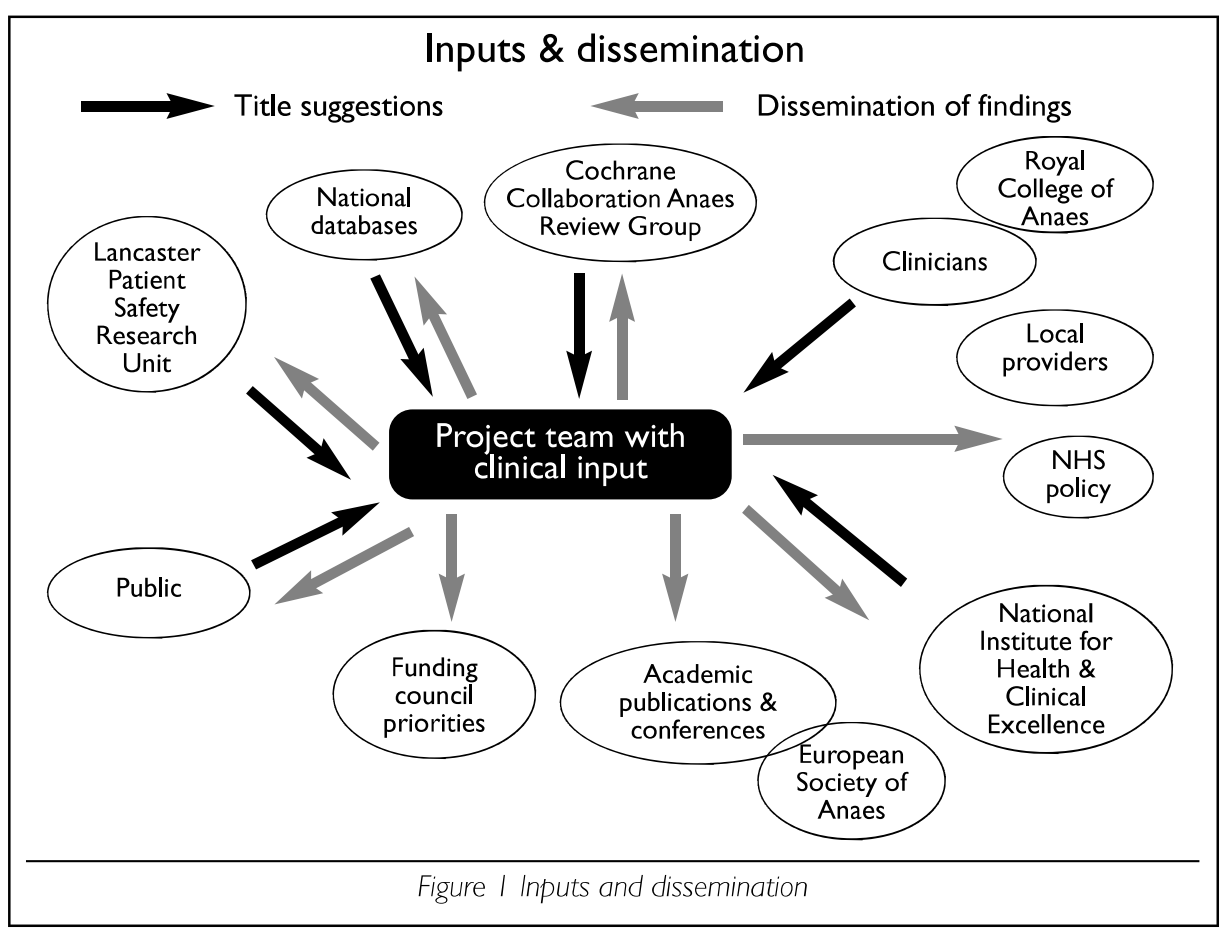




\section{PROJECT TEAM}

We started work in the autumn of $201 \mathrm{I}$ and are now in the last year of the grant. The core project team consists of:

- Prof Andy Smith, consultant anaesthetist at Royal Lancaster Infirmary and Director of the Lancaster Patient Safety Unit

- Dr Sue Hinder, RaFT Consulting and patient representative

- Mrs Sharon Lewis, systematic reviewer based at the Lancaster Patient Safety Unit

- Dr Amanda Nicholson, systematic reviewer based at the Faculty of Health and Medicine, University of Lancaster

- Dr Phil Alderson, Associate Director of Methodology, NICE

Other investigators on the grant are Dr Sue Harding

(Associate Medical Director), and Dr Ameeta Joshi (lead clinician for Head and Neck Services).

We would also like to record our appreciation to the following as co-authors and advisors to our projects:

- Dr Chris Coldwell, consultant anaesthetist

- Dr Gillian Campbell and Dr Stephanie Reed, clinical research fellows, Department of Anaesthesia

- Dr Andy Brammar, specialist trainee in anaesthesia

\section{TARGETS AND PROGRESS}

We are funded by the National Institute for Health Research $(\mathrm{NIHR})$ and the European Society for Anaesthesia (ESA). We have received $£ 420,000$ funding from the $\mathrm{NIHR}$ over three years, starting on I August 20 I I. We have obtained an additional grant from ESA for a 'Meta-analysis of enhanced recovery programmes in surgical patients'.

\section{WORK SO FAR}

We have 21 reviews in progress, addressing issues of safety, quality and productivity. We already have four reviews and seven protocols published in the Cochrane Library. ${ }^{(3-13)}$ Examples are shown in figure 2.

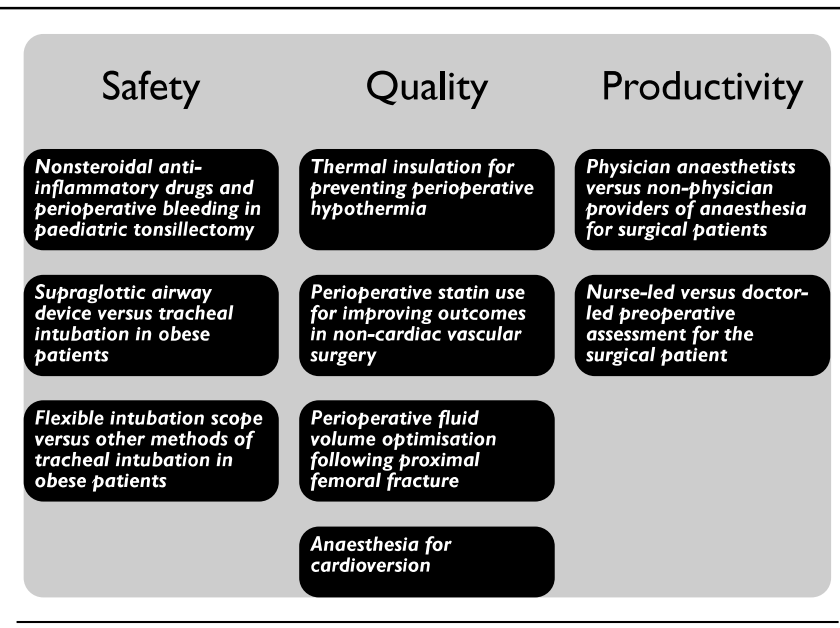

Figure 2 Examples of work so far

\section{COLLABORATORS WELCOME!}

We are keen to work with local NHS staff and patients. We would welcome suggestions for additional topics for reviews. Staff who we are able to involve in the review process will receive support and training. Please get in touch with us!

\section{CONTACT DETAILS}

Prof Andrew Smith, Director, Lancaster Patient Safety Research Unit, Royal Lancaster Infirmary, Ashton Road, Lancaster, LAI 4RP. Email: andrew.f.smith@mbht.nhs.uk

\section{REFERENCES}

I. Woodall NM, CookTM. National census of airway management techniques used for anaesthesia in the UK. $\mathrm{Br}$ J Anaesth 201 I; 106:266-71

2. Weiser TG, et al. Estimation of global volume of surgery. Lancet 2008;372:139-44

3. Alderson P, Campbell G, Smith AF, Warttig S. Pharmacological agents for preventing inadvertent perioperative hypothermia (Protocol). Cochrane Database Syst Rev 20 I2;(6):CD009906

4. Alderson P, Campbell G, Smith AF, Warttig S, Nicholson A, Lewis SR. Thermal insulation for preventing inadvertent perioperative hypothermia (Protocol). Cochrane Database Syst Rev 2012;(6):CD009908

5. Brammar A, Nicholson A, Trivella M, Smith AF. Perioperative fluid volume optimization following proximal femoral fracture (Review). Cochrane Database Syst Rev 2013;(9):CD003004

6. Campbell G, Alderson P, Smith AF, Warttig S. Interventions for treating inadvertent postoperative hypothermia (Protocol). Cochrane Database Syst Rev 2012;(6):CD009892

7. Campbell G, Alderson P, Smith AF, Warttig S. Warming of intravenous and irrigation fluids for preventing inadvertent perioperative hypothermia (Protocol). Cochrane Database Syst Rev 2012;(6):CD00989 I

8. Lewis SR, Nicholson A, Cardwell ME, Siviter G, Smith AF. Nonsteroidal anti-inflammatory drugs and perioperative bleeding in paediatric tonsillectomy (Review). Cochrane Database Syst Rev 2013; (7):CD00359 I

9. Lewis SR, Nicholson A, Smith AF. Physician anaesthetists versus non-physician providers of anaesthesia for surgical patients (Protocol). Cochrane Database Syst Rev 2013;(2):CD010357

10. Nicholson A, CookTM, Lewis SR, Smith AF. Tracheal intubation with a flexible intubation scope versus other intubation techniques for obese patients requiring general anaesthesia (Protocol). Cochrane Database Syst Rev 2013;(I):CD010320

II. Nicholson A, CookTM, Smith AF, Lewis SR, Reed SS. Supraglottic airway devices versus tracheal intubation for airway management during general anaesthesia in obese patients (Review). Cochrane Database Syst Rev 2013;(9):CD010105

12. Nicholson A, Lewis SR, Coldwell CH, Smith AF. Nurse-led versus doctor-led preoperative assessment for elective surgical patients requiring regional or general anaesthesia (Protocol). Cochrane Database Syst Rev 20 I2;(I0):CD0I0I 60

13. Sanders RD, Nicholson A, Lewis SR, Smith AF, Alderson P. Perioperative statin therapy for improving outcomes during and after noncardiac vascular surgery (Review). Cochrane Database Syst Rev 20 13;(7):CD00997I 